\title{
Coal Mine Super High Pressure Hydraulic Slotted Anti-reflection Technology and Applicable Conditions
}

\author{
Yongjiang Zhang ${ }^{1,2,3, a^{*}}$ and Zhanjin $\mathrm{Lu}^{2,3, \mathrm{~b}}$ \\ ${ }^{1}$ Anhui University of science and technology Huainan 232001 \\ ${ }^{2}$ National Key Laboratory of Gas Disaster Detecting, Preventing and Emergency Controlling, \\ Chongqing 400037, China \\ ${ }^{3}$ Chongqing Research Institute of China Coal Technology \& Engineering Group, Chongqing 400039, \\ China \\ azhangyj_1026@163.com, 'buzhanjin0357@126.com
}

Keywords: Ultra-high pressure; Hydraulic cutting; Suitable conditions

\begin{abstract}
With the increase of depth, coal mine gas control technology is harder, the existing means of prevention and control technology cannot completely meet the demand of deep well control. Coal mine hydraulic anti-reflection is important for prevention and control of technology, but because of the complexity of the coal mine coal seam occurrence condition and hydraulic change anti-reflection according to use classification for the purpose of coal seam water injection, hydraulic broaching, hydraulic pressure, hydraulic cutting, technology principle and application condition each have differences, analyses its working principle, the process characteristics of the different technologies used, in the coal mine area a better promotion of hydraulic technology, better service in the governance of gas disaster in coal mine.
\end{abstract}

\section{Introduction}

China is the world's coal and gas dynamic disaster, one of the most serious countries with fewer shallow coal resources, deep mine gas coal and rock dynamic disasters become one of the main problems of restricting coal mine safety and efficient production. Mechanism of deep mine gas coal and rock dynamic disasters to more complicated, only on coal seam gas extraction standards cannot completely solve the composite of coal and rock dynamic disaster, must be collected from coal seam gas drainage standard and unloading effective Angle to carry on the dynamic disaster prevention, in addition to mining protective coal seam group of regional pressure relief measures, but has yet to develop an effective regional pressure relief or crack anti-reflection measures, how to effectively unloading anti-reflection needs to be one of the key problems for coal industry[1-4].

Super high pressure hydraulic cutting seam technology is a high and new technology in recent years, high-speed development, at present in the mining industry, oil drilling, aerospace, construction and other aspects has been widely applied[5-7]. Using high pressure water jet can be used to wash, drilling, cutting, rock, etc., to reduce the cost and improve the working efficiency. High pressure hydraulic drill cut unloading anti-reflection technology, based on water power, coal washing, peeling, around the borehole increase the fractures in the coal, can greatly improve the gas flow in coal seam condition, create favorable conditions for gas extraction, changed the original stress and crack condition, coal in the coal and rock mass stress relaxation tension, as well as to weaken or eliminate the outstanding power, and can greatly change the physical and mechanical properties of coal seams, unloading, the outburst prevention effect, and improve the ability of permeability and the gas release, is one of the development direction of coal mine gas dynamic disaster prevention measures.

\section{Classification of Hydraulic Permeability Improved Technology}

Study and application on hydraulic pressure releasing and permeability improved on coal dynamic disasters prevention for the deep mining becomes hot spot, study on process, technology, equipment 
and effect evaluation continuously improve. Hydraulic permeability improved technology measure was divided into three groups[8-10].

The first kind: as the wetting agent, water can change mechanical properties of coal seam gas. Wetting coal seam can affect the factors causing outburst, such as mechanical properties and physical properties. Humidity, gas emission, gas pressure, and coal stress all will be changed and strength of outburst can be decreased.

Outburst prevention, rock burst prevention and coal dust prevention with water injection, and comprehensive measure about water injection after gas drainage, what are suitable for regional measures to coal seam in working face and uncovering coal in cross-cut.

The second kind: as the power, water can create new hole or fracture in coal seam, expand the original fracture of coal seam, and move coal seam, like ultra-high pressure hydraulic cutting, hydraulic fracturing, hydraulic loosening and high pressure water jet reaming. The characteristic of hydraulic measure is high pressure or large flow, which is more than the pressure of ground or breaking coal seam and the amount which coal absorbing and permeating, make coal seam rupture and move and change the stress of coal seam to release the pressure and drain gas, in order to achieve outburst and rock burst prevention.

Hydraulic cutting: Under cutting of ultra-high pressure water jet, fractures of coal in the drilling are reconstructed artificially, exposed area of coal seam was enlarged. Hydraulic cutting is suitable for pressure releasing and permeability improved for outburst with hard coal( $\mathrm{f}>0.5)$, rock burst, layer-through borehole in floor with compound dynamic disaster, uncovering coal in cross-cut and bedding borehole in large inclination working face.

Hydraulic extrusion: inject water in drilling with higher speed than permeating to break coal seam and make coal move towards face, and release the pressure and drain gas. Hydraulic extrusion is suitable for driving in coal tunnel which is easy to evoke outburst.

Hydraulic fracturing: it can be used in ground underground and most regions of face, and it suitable for pressure releasing and permeability improved for layer-through borehole in floor, bedding long drilling directional fracturing in face.

The third kind: as the partial power, water need to control potentiality of outburst with low requirement for pressure, like hydraulic flushing. Using bit cutting and water jet impacting, hydraulic flushing can break unstable balance between stress and gas in coal, make drilling jet orifice artificially. With coal and gas excretion, potentiality of outburst was released to prevent outburst. Hydraulic flushing is suitable for soft outburst coal $(\mathrm{f}<0.5)$ with potentiality and uncovering coal in cross-cut.

\section{Principle of Ultra-high Pressure Hydraulic Cutting}

Under cutting of ultra-high pressure water jet, fractures of coal in the drilling were reconstructed artificially, exposed area of coal seam was enlarged, gas flow state in coal seam was improved effectively to create favorable conditions for gas draining, original stress of coal seam was changed, pressure in coal seam was released uniform and sufficiently in a certain range(schematic diagram of principle of ultra-high pressure hydraulic cutting on pressure releasing and permeability improved is shown in Fig. 1), permeability of coal seam and gas releasing capability were improved to eliminate or decrease risks of coal seam outburst and rock burst.

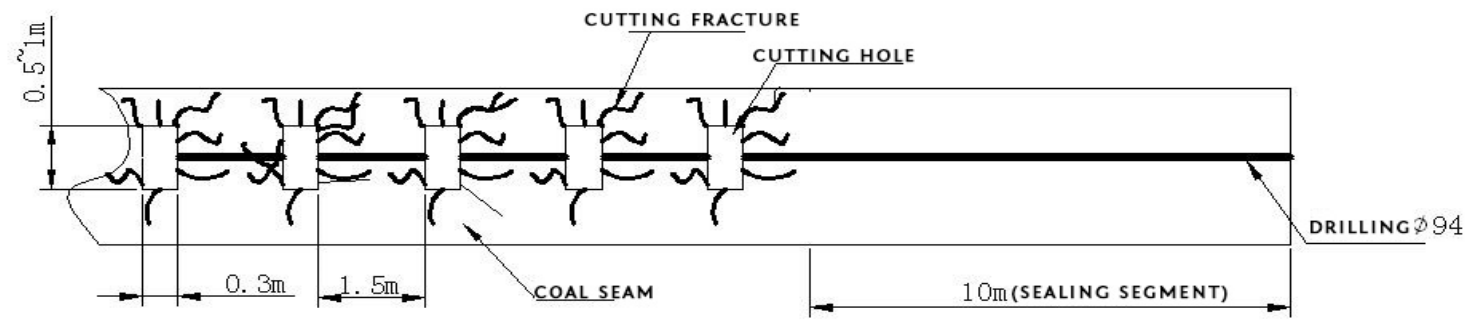

Figure 1. Principle of ultra-high pressure hydraulic cutting on pressure releasing and permeability improved 


\section{Characteristics of Ultra-high Pressure Hydraulic Cutting}

There are some characteristics of ultra-high pressure hydraulic cutting analyzed from technology:

(1) Ultra-high pressure hydraulic cutting makes large numbers of coal exhausted and provide space for expansion deformation of coal by cutting coal in the case of artificial control. Under the ground stress, coal around drilling expands and deforms, which makes ground stress move to all around and plays an important role in transferring local ground stress, meanwhile, new fractures are increased and connected to make cutting drilling and other drainage drilling connected which can attain pressure released and permeability improved integral area by using rheological behavior.

(2) For gas activity, there are not only large numbers of coal exhausted when ultra-high pressure hydraulic cutting working, but also influence range gradually expanded and porosity and permeability improved because of coal drilling expanding and deforming after cutting, which makes distant gas flow to drilling continuously, so that gas content of ton coal exhausted is much larger than it of original coal. Drainage efficiency can be increased largely and gas content of around cut coal can be effectively reduced with gas drainage. Hydraulic cutting plays an important role in eliminating outburst, accelerating gas resolved and decreasing coal and rock stress because of high stress relieved, gas content decreased and permeability improved.

(3) Brittle was weakened, plastic was increased, elastic potential energy was decreased when coal was wet. In addition, analytic velocity of residual gas and expansion energy of gas in coal was decreased.

(4) During tunneling and mining, wet coal can improve tunnel dust problems by increasing water content of coal, which can relieve dust problems on the coal mining activities.

\section{Summary}

(1)Hydraulic pressure relief anti-reflection technology, can greatly improve the gas flow in coal seam condition, create favorable conditions for gas extraction, changed the original stress and crack condition, coal can weaken or eliminate the striking power, and can greatly change the physical and mechanical properties of coal seams, unloading, the outburst prevention effect.

(2)According to different hydraulic anti-reflection technical characteristics, research of coal seam water injection, hydraulic punching, hydraulic fracturing, hydraulic cutting seam suitable conditions, provide the basis for the promotion of this technology.

\section{Acknowledgements}

Coal science research institute of science and technology innovation fund projects (2016ZYMS016), Deep coal mining influence and disaster prevention and control in anhui province key laboratory of open fund (KLDCMERDPC14101) support, Chongqing Institute of Coal Science Research Institute (Self-reliance general project 2015YBXM37) support.

\section{References}

[1] L.L Yuan, B.Q Lin and W Yang, (2015) "Research Progress and Development Direction of Gas Control with Mine Hydraulic Technology in China Coal Mine," Coal Science and Technology. J., (01): 45-49.

[2] X.H Li, X.C Wang and Y Kang, et al (2014) "Energy Characteristic and Dissipation in Transient Process of Hydraulic Cutting Seams System in Coal Seam," Journal of China Coal Society. J., (08): 1404-1408.

[3] J. Labus-T (1995) "Fluid Jet Technology," St. Louis: WJTA, M.

[4] Howe MS, Williams JEF (1978) "On the Noise Generated By an Imperfectly Expanded Supersonic Jet," Philosophical Transactions of the Royal Society of London. Series A, Mathematical and Physical Sciences. J., 289(1358): 271-314. 
[5] X.Z Meng, J.J Cao and Q He, et al (2009) "Study and Application on Hydraulic Highly Efficient Outburst Prevention Integration Technology," Mining Safety and Environmental Protection. J., (S1): 49-53.

[6] J.J Cao, X.Z Meng and Q He, et al (2009) "New Drilling and Reaming Integrated Technology with Hydraulic Outburst Prevention," Coal Science and Technology. J., 39(11): 40-44.

[7] M.B Chi (2015) "Experimental Study on Hydraulic Cutting Seam Prevention and Cure of Z.Y Xin Mines Rock Burst," Shan Xi: Tai Yuan University of Technology. D.

[8] C.S Zheng, Lin Baiquan and Yang Wei, et al (2014) "Hole-spraying Mechanism of Hydraulic Slotting Drilling and the Influence of Slotting Mode," Safety in Coal Mines. J., (01): 5-8+12.

[9] X.P Xin J.Y Zhang and Z.F Wang (2014) "Application of Pressure Relief and Permeability Increasing Technology with Rotating Slice Cutting Through Seam in Jiulishan Coal Mine," Safety in Coal Mines. J., (12): 83-84+88.

[10] L.Y Yu (2016) "Hydraulic Cutting Technology Control in High Gassy Seam". Inner Mongolia Coal Economy. J., (01): 90-91+128. 